National Marine

Fisheries Service

NOAA
Fishery Bulletin

¿ established in 1881 \%
Spencer F. Baird

First U.S. Commissioner of Fisheries and founder of Fishery Bulletin

\begin{abstract}
The genetic population structure of the polkadot skate (Dipturus chinensis) around Japan was examined by using mitochondrial $(\mathrm{mt})$ cytochrome (cyt) $b$ gene sequences and polymorphic microsatellite (simple sequence repeat [SSR]) loci. Results of phylogenetic analysis based on $\mathrm{mt}$ cyt $b$ gene sequences reveal 2 major lineages, clades A and B. Clade A consists of populations in the Sea of Japan and the East China Sea. Clade B contains populations in the Pacific Ocean and is divided into 2 subclades, clades $\mathrm{B} 1$ and B2, which correspond to the populations along the southern and northern coasts of Japan, respectively. This genetic differentiation is also supported by results from SSR analysis. The divergence of clades A and B may reflect isolation of the East China Sea from the Pacific Ocean in the Early Pleistocene. After diverging from clade A, clade B might have extended its distribution northward along the Pacific coast of Japan and divided into clades $\mathrm{B} 1$ and $\mathrm{B} 2$ in the Middle Pleistocene. The polkadot skate is clearly structured into 3 genetically discrete populations around Japan that should be treated as independent management units for management of this species in the future.
\end{abstract}

\section{Genetic population structure of the polkadot skate (Dipturus chinensis) around Japan, based on mitochondrial DNA sequences and polymorphic microsatellite loci}

\author{
Takahiro Kusaka, ${ }^{1,5}$ \\ Kojiro Hara ${ }^{2}$ \\ Keisuke Furumitsu ${ }^{2}$ \\ Shinji Uehara ${ }^{3}$ \\ Yuta Yagi ${ }^{4}$ \\ Atsuko Yamaguchi ${ }^{2}$ \\ Naoki Yagishita (contact author) ${ }^{2}$ \\ Email address for contact author: n-yagi@nagasaki-u.ac.jp \\ ${ }^{4}$ Niigata Field Station \\ Demersal Fish Resources Division \\ Fisheries Stock Assessment Center \\ Fisheries Resources Institute \\ Japan Fisheries Research and Education \\ Agency \\ 1-5939-22 Suido-cho \\ Chuou-ku, Niigata 951-8121, Japan \\ ${ }^{5}$ Nishinihon Institute of Technology \\ 9-30 Wakamatsu-cho \\ Kochi 781-0812, Japan \\ ${ }^{1}$ Laboratory for Aquatic Biology \\ 3327-204 Nakamachi \\ Nara 631-8505, Japan \\ Graduate School of Fisher
Environmental Sciences \\ Nagasaki University \\ Nagasaki 852-8521, Japan \\ Fisheries Stock Assessment Cen \\ Education Agency \\ 2-12-4 Fukuura \\ Kanazawa, Yokohama 236-8648, Japan
}

The polkadot skate (Dipturus chinensis) is distributed along the coast of Japan from Hokkaido southward to Kyushu, the East China Sea, the Korean Peninsula, and Taiwan (Fig. 1). It inhabits sandy to muddy bottoms at depths of 20-320 m, mostly shallower than 150 m (Yamada et al., 2007, 2009; Hatooka et al., 2013; Last et al., 2016). Until recently, the species had been confused with the Kwangtung skate ( $D$. kwangtungensis), which occurs in the South China Sea (Last and Lim, 2010). However, Last et al. (2016) reclassified the species as $D$. chinensis on the basis of the differences in morphological characteristics.
The polkadot skate is caught mostly by bottom-trawl fishing vessels in the East China Sea (Jeong and Ishihara, 2009) and processed mainly for dried and paste products (Yamada et al., 2007). The annual catch of rajid species, including the polkadot skate, in the East China Sea peaked at 17,000 metric tons ( $\mathrm{t}$ ) in 1948 but has declined to approximately $100 \mathrm{t}$ in recent years (Tokimura et al., 1998; Hara et al., 2014). Moreover, the polkadot skate was commonly found in Korean fish markets before 2000; however, presently, very few can be found in those markets (Jeong and Ishihara, 2009). The decrease in abundance of skate

\footnotetext{
author (or authors) and do not necessarily reflect the position of the National Marine Fisheries Service, NOAA.

Manuscript submitted 4 February 202

Online publication date: 19 July 2021. doi: 10.7755/FB.119.2-3.1 The views and opinions expressed or
implied in this article are those of the
}

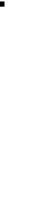




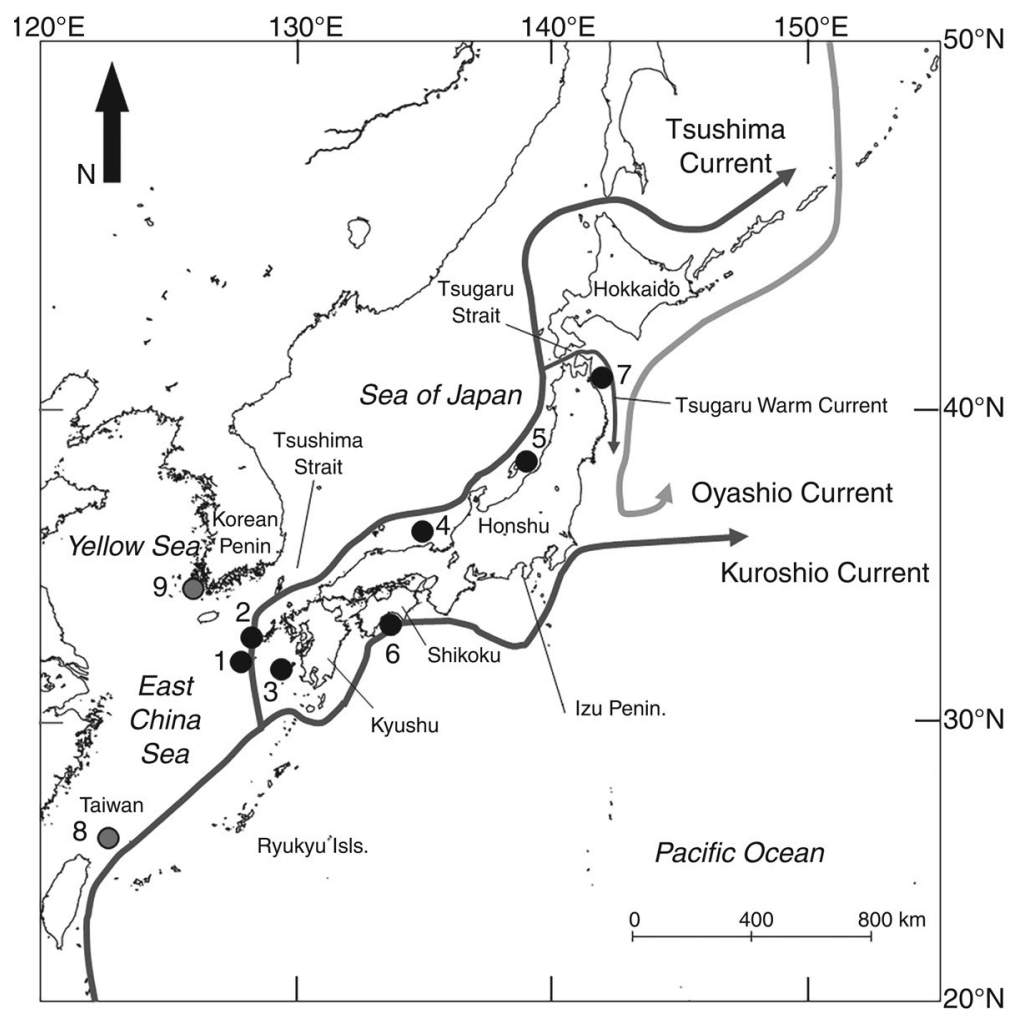

Figure 1

Map of the 7 locations (black circles) around Japan where polkadot skate (Dipturus chinensis) were collected during 2010-2017. Also shown are the 2 locations (gray circles) of the populations for which DNA sequences were obtained through the International Nucleotide Sequence Database Collaboration. The dark and light gray lines with arrows indicate the flow and direction of oceanic currents. The numerals next to the circles correspond to the 9 locations: (1) Danjo Islands, (2) Goto Islands, (3) Koshiki-jima Islands, (4) Kyoto Prefecture, (5) Niigata Prefecture, (6) Kochi Prefecture, (7) Aomori Prefecture, (8) Taiwan, and (9) Korean Peninsula. Isls.=Islands; Penin.=Peninsula.

Stéphan et al. ${ }^{1}$; Frodella et al., 2016; Im et al., 2017; Vargas-Caro et al., 2017; Ferrari et al., 2018; Weltz et al., 2018; Misawa et al., 2019a, 2019b, 2020). The results of most studies reveal significant population structuring shaped by historical, geographical, and environmental factors, indicating that Rajidae generally have low dispersal ability.

Japan is surrounded by complicated oceanic currents (Fig. 1): the Kuroshio Current flows from east of the Philippines past Taiwan and the Ryukyu Islands to the Pacific coast of Kyushu, Shikoku, and southern Honshu of Japan; the Tsushima Current, which branches off from the Kuroshio Current off southern Kyushu, flows northward along the western coast of Honshu; and the Oyashio Current originates in the Arctic Ocean and flows southward past the Bering Sea to the Pacific coast of Hokkaido and northern Honshu. The population structures of rajid species as well as of various marine animals around Japan, it has been suggested, are affected by those currents (Kojima et al., 1997, 2004; Akihito et al., 2008; Kokita and Nohara, 2011; Han et al., 2012; Hirase et al., 2012; Hirase and Ikeda, 2014). For the ocellate spot skate (Okamejei kenojei), the distribution of which is similar to that of the polkadot skate, the force of warm currents, the Tsushima and Kuroshio Currents, has been reported to prevent dispersal of individuals (Misawa et al., 2019b). The Tsushima Current, as a dispersal barrier, has shaped the population structure of the mottled skate (Beringraja pulchra), according to Misawa et al. (2019a). There is a possibility that the species, including the polkadot skate, may result from their life history traits; as members of Elasmobranchii, they have slow growth rates, late attainment of sexual maturity, long life spans, and low fecundity (Brander, 1981; Dulvy et al., 2000; Hara et al., 2018a), making them vulnerable to exploitation.

Recently, basic life history traits, such as age, growth, and age at sexual maturity, and dietary habits of the polkadot skate were examined to establish conservation and management strategies for this species (Hara et al., 2018a, 2018b). Genetic information, such as population structure, is important for fisheries management and development of conservation policies for elasmobranch species (Domingues et al., 2018). To date, several studies on genetic population structure have been conducted for several species of Rajidae (Chevolot et al., 2006a, 2006b, 2007; Griffiths et al., 2010, 2011; population structure of the polkadot skate is also affected by the currents around Japan.

In this study, we examined the genetic population structure of the polkadot skate around Japan by using partial sequences of mitochondrial (mt) cytochrome (cyt) $b$ gene and polymorphic microsatellite (simple sequence repeat [SSR]) loci because those molecular markers will provide information that can help guide fishery management and

\footnotetext{
${ }^{1}$ Stéphan, E., C. Hennache, A. Delamare, N. Leblanc, V. Legrand, G. Morel, E. Meheust, and J. L. Jung. 2014. Length at maturity, conversion factors, movement patterns and population genetic structure of undulate ray (Raja undulata) along the French Atlantic and English Channel coasts: preliminary results, $16 \mathrm{p}$. Working paper presented at the 2014 Working Group on Elasmobranch Fishes (WGEF) meeting; Lisbon, 17-26 June. [Available from ICES Secretariat, H. C. Andersens Blvd. 44-46, 1553 Copenhagen, Denmark.]
} 


\section{Table 1}

Sampling location, number of specimens, total length (range and mean), sampling depth, and capture date of the polkadot skate (Dipturus chinensis) collected during 2010-2017 from 7 locations in the East China Sea, Sea of Japan, and Pacific Ocean around Japan. For populations at 2 other locations, Taiwan and the Korean Peninsula, DNA sequences were obtained through the International Nucleotide Sequence Database Collaboration. The specific location for the sequences for Taiwan is unknown, and sequences for the Korean Peninusula are for polkadot skate from Jindo, off the southwestern coast of the peninsula, near the boundary of the East China Sea and the Yellow Sea.

\begin{tabular}{|c|c|c|c|c|c|}
\hline \multirow[b]{2}{*}{ Location } & \multirow{2}{*}{$\begin{array}{c}\text { No. of } \\
\text { specimens }\end{array}$} & \multicolumn{2}{|c|}{ Total length (mm) } & \multirow{2}{*}{$\begin{array}{l}\text { Sampling depth } \\
(\mathrm{m})\end{array}$} & \multirow[b]{2}{*}{ Capture date } \\
\hline & & Range & Mean & & \\
\hline \multicolumn{6}{|l|}{ East China Sea } \\
\hline Danjo Islands & 48 & $189-684$ & 473 & $130-150$ & April 2010-April 2015 \\
\hline Goto Islands & 18 & $370-643$ & 523 & 203 & January 2014 \\
\hline Koshiki-jima Islands & 1 & 514 & - & Unknown & November 2013 \\
\hline \multicolumn{6}{|l|}{ Sea of Japan } \\
\hline Kyoto Prefecture & 47 & $102-638$ & 335 & $110-170$ & April 2014-July 2014 \\
\hline Niigata Prefecture & 49 & $116-701$ & 485 & $120-160$ & August 2013-August 2014 \\
\hline \multicolumn{6}{|l|}{ Pacific Ocean } \\
\hline Kochi Prefecture & 23 & $125-584$ & 356 & $150-320$ & November 2015-January 2016 \\
\hline Aomori Prefecture & 26 & $335-775$ & 537 & $160-180$ & February 2017-March 2017 \\
\hline Taiwan & 1 & - & - & - & - \\
\hline Korean Peninsula & 1 & - & - & - & - \\
\hline
\end{tabular}

conservation efforts. On the basis of mt cyt $b$ sequences, we also estimated the evolutionary history of this species, information that is important for delineation of managing units that should be managed independently to ensure the viability of the species (Moritz, 1994, 2002; Palsbøll et al., 2007).

\section{Materials and methods}

\section{Sampling and DNA extraction}

A total of 212 polkadot skate (102-775 $\mathrm{mm}$ in total length [TL]; mean: $444 \mathrm{~mm}$ TL) were collected from 7 locations around Japan: 3 locations in the East China Sea, the Danjo Islands (number of samples $[n]=48)$, Goto Islands $(n=18)$, and Koshiki-jima Islands $(n=1) ; 2$ locations in the Sea of Japan, Kyoto Prefecture $(n=47)$ and Niigata Prefecture $(n=49)$; and 2 locations in the Pacific Ocean, Kochi Prefecture $(n=23)$ and Aomori Prefecture $(n=26)$ (Table 1, Fig. 1). In addition, individuals of 2 other species of Dipturus, the bigtail skate (D. macrocaudus) and the acutenose skate (D. tengu), were collected from Kochi Prefecture so that these species could serve as outgroups for phylogenetic analysis. Samples were obtained from depths of 110-320 m by using bottom or beam trawls between 2010 and 2017 .

Muscle tissue was dissected from each fish and stored, either frozen at $-20^{\circ} \mathrm{C}$ or in $99.5 \%$ ethanol, until DNA extraction. Total genomic DNA was extracted by using the
DNeasy Blood \& Tissue Kit ${ }^{2}$ (QIAGEN, Hilden, Germany) following the manufacturer's protocol.

\section{Mitochondrial DNA analyses}

We used a polymerase chain reaction (PCR) to amplify approximately 1200 base pairs of the mt cyt $b$ gene, with the following primers: GLU-L-Dipturus (5'-TCT GAA AAA CTA CCG TTG TTA-3') and CB6THR-H-Dipturus (5'-CTC CAA TCT TTG GTT TAC AAG-3'). The design of the primers was based on a primer pair, GLU-L and CB6THR-H (Palumbi et al., 2002), with reference to the cyt $b$ gene sequences of skate species registered in the DNA Data Bank of Japan, which is part of the International Nucleotide Sequence Database Collaboration: the polkadot skate (registered as D. kwangtungensis; accession number KF318309; Jeong et al., 2015), the thorny skate (Amblyraja radiata) (accession number AF106038; Rasmussen and Arnason, 1999), the ocellate spot skate (accession number AY525783; Kim et al., 2005), the Korean skate (Hongeo koreanus) (accession number KC914433; Jeong et al., 2014), and the longnose skate (Beringraja rhina) (registered as Raja rhina; accession number KC914434; Jeong and Lee, 2015). Polymerase chain reactions were conducted by using a PCR Thermal

\footnotetext{
${ }^{2}$ Mention of trade names or commercial companies is for identification purposes only and does not imply endorsement by the National Marine Fisheries Service, NOAA.
} 
Cycler Dice Gradient (TaKaRa Bio, Shiga, Japan), each with $10 \mu \mathrm{L}$ of reaction solution containing $10 \mathrm{ng}$ template DNA, $0.5 \mu \mathrm{M}$ of each primer, $0.2 \mathrm{mM}$ dNTP mixture, 1× PCR buffer (10 mM Tris-HCl pH 8.3, $50 \mathrm{mM} \mathrm{KCl,}$ and $1.5 \mathrm{mM} \mathrm{MgCl}_{2}$ ), and $0.5 \mathrm{U}$ Ex Taq DNA polymerase (TaKaRa Bio).

The reaction conditions were as follows: an initial denaturation at $94^{\circ} \mathrm{C}$ for $2 \mathrm{~min} ; 30$ cycles of denaturation at $94^{\circ} \mathrm{C}$ for $30 \mathrm{~s}$, annealing at $62^{\circ} \mathrm{C}$ for $30 \mathrm{~s}$, and extension at $72^{\circ} \mathrm{C}$ for $1 \mathrm{~min}$; and a final extension of $72^{\circ} \mathrm{C}$ for $10 \mathrm{~min}$. The PCR products, purified by using illustra ExoStar (Cytiva, Malborough, MA), were sequenced on an Applied Biosystems ABI Prism 3130 XL Genetic Analyzer (Thermo Fisher Scientific Inc., Waltham, MA), with the Applied Biosystems BigDye Terminator Cycle Sequencing Kit (vers. 3.1; Thermo Fisher Scientific Inc.) and the primers used in the PCR. Forward and reverse sequences were connected by using GENETYX, vers. 8 (GENETYX Corp., Tokyo, Japan). All sequences have been deposited in the DNA Data Bank of Japan under accession numbers LC547089-LC547120.

The DNA sequences and the published sequences of polkadot skate from waters around Jindo Island, off the southwestern coast of the Korean Peninsula, near the boundary of the East China Sea and the Yellow Sea (registered as D. kwangtungensis; accession number KF318309; Jeong et al., 2015) and from Taiwan (the specific locality is unknown; accession number EU870495; Su and Hwang, available from the DNA Data Bank of Japan at website) were aligned with CLUSTAL W, vers. 2.1 (Larkin et al., 2007). Haplotype diversity $(h)$ (Nei, 1987) and nucleotide diversity $(\pi)$ (Nei, 1987) were calculated for each geographic population, meaning the population at each sampling location, by using Arlequin, vers. 3.5 (Excoffier and Lischer, 2010).

Using the bigtail skate (LC547121; this study), the acutenose skate (accession number LC547122; this study), and the roughskin skate (D. trachydermus) (accession number KR152643; Vargas-Caro et al., 2016) as outgroups, we performed phylogenetic analysis with MEGA, vers. 6.0 (Tamura et al., 2013). The best nucleotide substitution model was determined by using Bayesian information criterion. Subsequently, the maximum likelihood tree of haplotypes was constructed from evolutionary distances calculated by using the Tamura-Nei model (Tamura and Nei, 1993) with the $G$ parameter (ensuring heterogeneous rates across sites following the gamma distribution) (TN93+G model). Confidence values were estimated through bootstrapping analysis (Felsenstein, 1985) with 1000 replications. The time since lineage divergence $(t)$ was estimated from net average distances between lineages $\left(d_{\mathrm{A}}\right)$ (Nei and Li, 1979; Nei and Miller, 1990) on the basis of the following relationship: $t=d_{\mathrm{A}} / 2 \mu$, where $\mu$ is the lineage mutation rate. Values of $d_{\mathrm{A}}$ were calculated by using $p$-distances, the proportion $(p)$ of nucleotide sites at which 2 sequences being compared are different, determined with MEGA. We assumed a divergence rate of $1.0-1.6 \%$ per million years, as this rate has been suggested for the mt cyt $b$ gene of a species of Raja
(Chevolot et al., 2006b). A minimum spanning network of haplotypes was constructed on the basis of the minimum sequence difference by using TCS, vers. 1.21 (Clement et al., 2000).

A hierarchical analysis of molecular variance (AMOVA) (Excoffier et al., 1992) was run in Arlequin to estimate the partitioning of genetic variation within and between populations (or groups). We assumed different groupings of locations to find the optimal grouping of locations with the highest value of molecular genetic diversity among geographic groups $\left(\Phi_{\mathrm{CT}}\right)$. The pairwise values of molecular genetic diversity among populations $\left(\Phi_{\mathrm{ST}}\right)$ were calculated, and their significance was tested with 10,000 permutations and adjusted with a sequential Bonferroni correction (Rice, 1989).

Analysis of mismatch distribution was performed with Arlequin to infer the recent demographic history of the samples and to test the fit of the observed distribution to that expected under the sudden expansion model. The goodness of fit between the observed and expected distributions was tested by using the sum of squared deviations (Schneider and Excoffier, 1999) and Harpending's raggedness index (Harpending, 1994). The demographic parameters of time since expansion in units of mutational time and population size before $\left(\theta_{0}\right)$ and after $\left(\theta_{1}\right)$ a rapid change in population size in units of mutational time (Rogers and Harpending, 1992; Schneider and Excoffier, 1999) were obtained by using a parametric bootstrap approach with 10,000 replications. Neutrality of the sequence variation was verified by using Tajima's $D$ statistic (Tajima, 1989a, 1989b) and Fu's $F_{\mathrm{S}}$ test (Fu, 1997), conducted in Arlequin with 10,000 simulated samples.

We constructed a Bayesian skyline plot (BSP) (Drummond et al., 2005) with the TN93+G model to estimate past dynamics in the female effective population size $\left(N_{\mathrm{e}}\right)$ multiplied by the generation interval through time, using BEAST, vers. 2.5.0 (Bouckaert et al., 2014). Each Markov chain Monte Carlo process was based on a run of 20 million generations, and genealogies were sampled every 1000 generations. Of the sampled genealogies, $10 \%$ were discarded as burn-in. The divergence rate of $1.3 \%$ per million years was applied under the strict molecular clock model. The convergence of parameters was visually checked with effective sample sizes of estimates for all relevant parameters over 200 with TRACER, vers. 1.7.1 (Rambaut et al., 2018). The parameter sum (indicators.alltrees) that estimated the number of population change steps was used to check for the most likely numbers of demographic changes.

\section{Microsatellite analyses}

A PCR was performed to amplify each of the following 7 SSR loci: LERI21, LERI26, LERI33, LERI34, LERI44, LERI50, and LERI63 (El Nagar et al., 2010). Polymerase chain reactions were carried out by using a PCR Thermal Cycler Dice Gradient, each with $10 \mu \mathrm{L}$ of reaction solution containing $10 \mathrm{ng}$ template DNA, $0.5 \mu \mathrm{M}$ of each primer, $0.2 \mathrm{mM}$ dNTP mixture, $1 \times$ PCR buffer $(10 \mathrm{mM}$ Tris$\mathrm{HCl} \mathrm{pH} \mathrm{8.3,} 50 \mathrm{mM} \mathrm{KCl}$, and $1.5 \mathrm{mM} \mathrm{MgCl}_{2}$ ), and $0.5 \mathrm{U}$ 
Ex Taq DNA polymerase. The reaction conditions were as follows: an initial denaturation at $94^{\circ} \mathrm{C}$ for $3 \mathrm{~min} ; 30$ cycles of denaturation at $94^{\circ} \mathrm{C}$ for $30 \mathrm{~s}$, annealing at $53^{\circ} \mathrm{C}$ (LERI26, LERI33, LERI50, and $L E R I 63)$ or $57^{\circ} \mathrm{C}$ (LERI21, LERI34, and LERI44) for $30 \mathrm{~s}$, and extension at $72^{\circ} \mathrm{C}$ for $30 \mathrm{~s}$; and a final extension step of $72^{\circ} \mathrm{C}$ for $10 \mathrm{~min}$. Forward primers were labelled with the fluorescent dyes FAM, VIC, NED, or PET (Thermo Fisher Scientific Inc.). Fragments were sized on an automated DNA sequencer, the ABI Prism 3130 XL Genetic Analyzer, by using dye-labeled Applied Biosystems GeneScan 600 LIZ Size Standard (Thermo Fisher Scientific Inc.), and scored by using the Applied Biosystems software Peak Scanner, vers. 1.0 (Thermo Fisher Scientific Inc.).

Micro-Checker (vers. 2.2.3; Van Oosterhout et al., 2004) was used for identifying possible genotyping errors (i.e., stuttering, large allele dropout, and null alleles) within the SSR data set by using 1000 randomizations. Linkage disequilibrium for all loci was calculated by using GENEPOP, vers. 4.2 (Raymond and Rousset, 1995; Rousset, 2008). The observed $\left(H_{\mathrm{O}}\right)$ and expected $\left(H_{\mathrm{E}}\right)$ heterozygosities were calculated by using Arlequin. Deviations of genotypic distributions from the Hardy-Weinberg equilibrium (exact test) (Guo and Thompson, 1992) within each sampling location, by locus, were tested by using Arlequin along with a sequential Bonferroni correction (Rice, 1989), to adjust the significance level. Allelic diversity assessed as allelic richness $\left(A_{\mathrm{R}}\right)$ was calculated by using FSTAT, vers. 2.9.3.2 (Goudet, 2002). The levels of genetic diversity within and among the geographic populations were tested by hierarchical AMOVA, as implemented in Arlequin. In these microsatellite analyses, we assumed different groupings of locations to find the optimal grouping of locations with the highest value of molecular genetic diversity among geographic groups $\left(R_{\mathrm{CT}}\right)$, a value analogous to $\Phi_{\mathrm{CT}}$ in the mtDNA analyses. The pairwise values of molecular genetic diversity among populations $\left(R_{\mathrm{ST}}\right)$, values analogous to $\Phi_{\mathrm{ST}}$ in the mtDNA analyses, were calculated, and their significance was tested with 10,000 permutations and adjusted with a sequential Bonferroni correction (Rice, 1989).

\section{Results}

\section{Mitochondrial DNA analyses}

A 931-base-pair fragment of the mt cyt $b$ gene was obtained from 214 polkadot skate from 9 locations (Table 1, Fig. 1). There were 53 polymorphic sites, and transitions and transversions were observed at 49 and 4 of these sites, respectively.

\section{Table 2}

Number of samples $(n)$, number of haplotypes $(H)$, haplotype diversity $(h)$, and nucleotide diversity $(\pi)$ estimated from mitochondrial cytochrome $b$ gene (Dipturus chinensis) also provided for populations of Taiwan and the Korean Peninsula for which were obtained through the International Nucleotide Sequence

$\begin{array}{lcccc}\text { Clade A } & & & & \\ \text { Danjo Islands } & 48 & 13 & 0.884(0.028) & 0.0031(0.002) \\ \text { Goto Islands } & 18 & 8 & 0.817(0.073) & 0.0023(0.001) \\ \text { Kyoto Prefecture } & 47 & 6 & 0.617(0.072) & 0.0023(0.001) \\ \text { Niigata Prefecture } & 49 & 6 & 0.521(0.067) & 0.0019(0.001) \\ \text { Koshiki-jima Islands } & 1 & 1 & - & - \\ \quad \begin{array}{l}\text { Taiwan } \\ \text { Korean Peninsula }\end{array} & 1 & 1 & - & - \\ \quad \text { Clade B1 } & 1 & 1 & - & - \\ \quad \text { Kochi Prefecture } & 23 & 3 & 0.245(0.113) & 0.0005(0.000) \\ \quad \begin{array}{l}\text { Clade B2 } \\ \text { Aomori Prefecture }\end{array} & 26 & 7 & 0.726(0.069) & 0.0014(0.001)\end{array}$

Genetic variation within populations Within 6 of the 9 geographic populations, excluding those at the Koshikijima Islands, Taiwan, and the Korean Peninsula (each with a sample size of only 1 individual), the number of haplotypes ranged from 3 to 13 haplotypes (Table 2). The number of haplotypes within each geographic population in the Sea of Japan (6 haplotypes in the populations in both Kyoto Prefecture and Niigata Prefecture) was lower than the number in the East China Sea (13 and 8 haplotypes in the populations at the Danjo Islands and Goto Islands, respectively). Additionally, the numbers in the Pacific Ocean ( 3 and 7 haplotypes in the populations in Kochi and Aomori Prefectures, respectively) were lower than those in the East China Sea. The $h$ values were high in all the geographic populations (0.521-0.884), except for in the population in Kochi Prefecture (0.245). The $\pi$ values were low in all geographic populations $(0.0005-$ 0.0031), with the values in the Pacific Ocean (0.00050.0014) lower than those in the East China Sea and the Sea of Japan (0.0019-0.0031). The $h$ and $\pi$ values in the East China Sea and the Sea of Japan gradually decrease among populations from the Danjo Islands northward to Niigata Prefecture.

Phylogenetic relationships among haplotypes A total of 34 haplotypes were defined. Among them, 8 haplotypes were shared between populations in at least 2 different locations, accounting for $65.0 \%$ of all observations; 12 haplotypes were found in more than 1 specimen from 1 location; and the remaining 14 haplotypes were singletons (Figs. 2 and 3).

The creation of a maximum likelihood tree of haplotypes (Fig. 2) revealed 2 major lineages, clades $\mathrm{A}$ and 


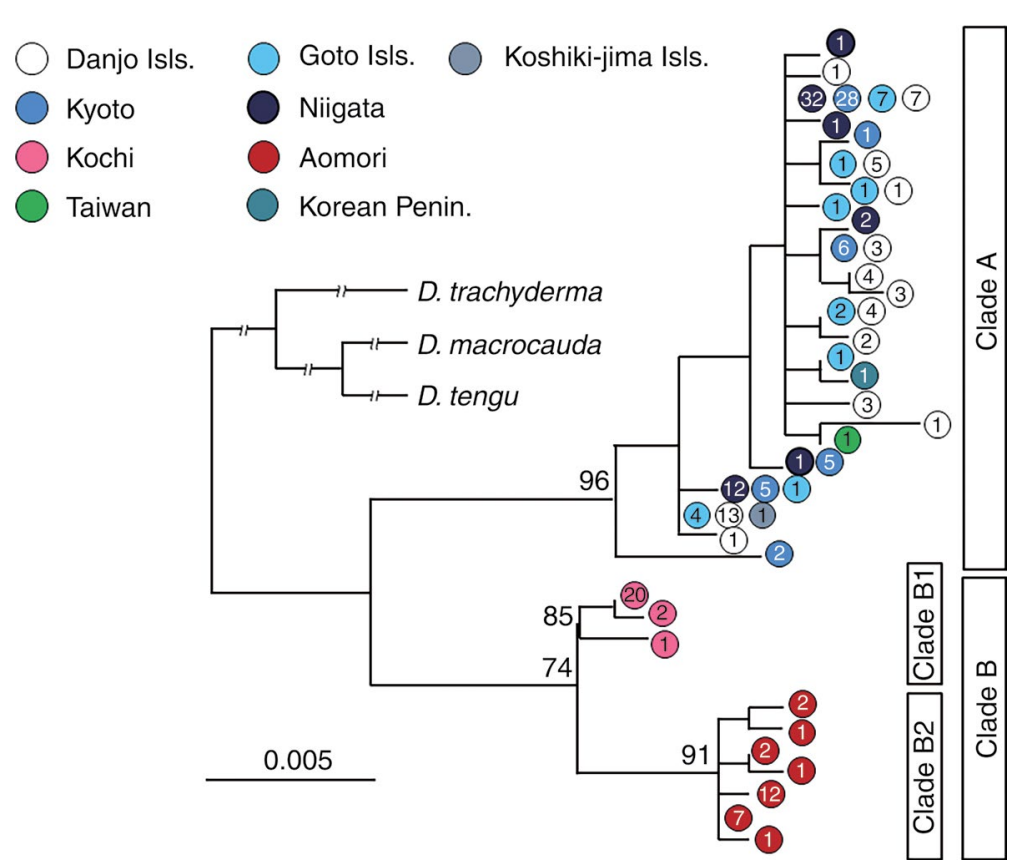

Figure 2

Maximum likelihood tree of haplotypes based on phylogenetic analysis of the mitochondrial cytochrome $b$ gene sequences (931 base pairs) of 214 polkadot skate (Dipturus chinensis). Sequences were obtained from specimens caught at 7 locations around Japan, in the East China Sea, Sea of Japan, and Pacific Ocean, during 2010-2017 or were obtained through the International NucleKorean Peninsula. The evolutionary distances were calculated by using the TN93+ $G$ model. Numerals at nodes indicate the bootstrap probability for clades A, B, B1, and B2. Numerals in circles indicate the number of individuals sharing the same haplotype. The roughskin skate (D. trachydermus), bigtail skate $(D$. macrocaudus), and acutenose skate $(D$. tengu) served as outgroups for phylogenetic analysis. The bar in the bottom-left corner indicates evolutionary distance. Isls.=Islands; Penin.=Peninsula. otide Sequence Database Collaboration for populations in Taiwan or off the

years ago (MYA). The uncorrected $p$ distance between clade B1 and clade B2 was 0.008 , and the divergence time was estimated to be $0.50-0.80$ MYA.

The minimum spanning network of the haplotypes is given in Figure 3. Haplotypes were divided into 2 groups, group A and group B, with the latter subdivided into 2 subgroups, group B1 and group $\mathrm{B} 2$, which correspond to clades $\mathrm{A}, \mathrm{B} 1$, and $\mathrm{B} 2$ in the maximum likelihood tree, respectively (Fig. 2). The 10 haplotypes of group B are separated from those of group A by a minimum of 15 mutations. The 3 haplotypes of group B1 are separated from those of group B2 by a minimum of 5 mutations. Group A consists of the most dominant haplotype, a1 ( $n=74$, $44.8 \%$ of the group), 9 haplotypes that are shared with more than 2 individuals (haplotypes a2-a10), and 14 rare haplotypes that were found in only 1 or 2 individuals. Group B1 includes 1 dominant haplotype, b1, and 2 rare haplotypes that connect with haplotype b1 by 1 and 3 mutations. Group B2 consists of 2 nonrare haplotypes (b2 and b3) and of 5 rare haplotypes connected to each other by 1 or 2 mutations.

Geographic distribution of haplotypes Haplotype frequencies in the 9 locations are shown in Figure 4. The population in the Danjo Islands consists of 8 nonrare haplotypes (a1, a2, a4-a6, and a8-a10) and 5 rare haplotypes, with haplotype a 2 being dominant $(27.1 \%$ of samples). The population in the Goto Islands comprises 5 non-rare (a1-a3, a5, and a6) and 3 rare haplotypes, with

$\mathrm{B}$, as indicated by high values of bootstrap probability (96\% and $74 \%$, respectively). Clade $\mathrm{B}$ is divided into 2 subclades, clades $\mathrm{B} 1$ and $\mathrm{B} 2$, with high values of bootstrap probability ( $85 \%$ and $91 \%$, respectively). Clades A, B1, and B2 consist of 24, 3, and 7 haplotypes, respectively. Clade A comprises the populations in the East China Sea (populations at the Danjo Islands and Goto Islands, as well as 1 individual from the Koshiki-jima Islands), the Sea of Japan (populations in the Kyoto and Niigata Prefectures), as well as 1 individual each from Taiwan and the Korean Peninsula ( $n=165,77.1 \%$ of all samples). Clades B1 and B2 consist of the populations along the southern (Kochi Prefecture: $n=23,10.7 \%$ of all samples) and northern (Aomori Prefecture: $n=26,12.1 \%$ of all samples) Pacific coasts of Japan, respectively. The net average distance (uncorrected $p$-distance) between clade $\mathrm{A}$ and clade B was 0.021 . Applying the divergence rate of 1.0-1.6\% per million years, we estimated that clade A and clade $\mathrm{B}$ diverged from each other 1.31-2.10 million haplotype a1 as the dominant haplotype (38.9\% of samples). The population in Kyoto Prefecture includes 4 nonrare (a1, a3, a4, and a7) and 2 rare haplotypes, with the dominant haplotype being a1 (59.6\% of samples). The population in Niigata Prefecture consists of 3 non-rare (a1, a3, and a7) and 3 rare haplotypes, with haplotype a1 as the dominant haplotype ( $65.3 \%$ of samples). In the East China Sea and the Sea of Japan, the frequency of haplotype a1 gradually increased from the Goto Islands (38.9\% of samples) northward to Niigata Prefecture (65.3\% of samples). The population in Kochi Prefecture includes 1 dominant (b1: 87.0\% of samples) and 2 rare haplotypes. The population in Aomori Prefecture consists of 2 non-rare (b2 and b3) and 5 rare haplotypes, with haplotype b2 being the dominant haplotype $(46.2 \%$ of samples).

Genetic differentiation among populations Samples from the Koshiki-jima Islands, Taiwan, and the Korean Peninsula 


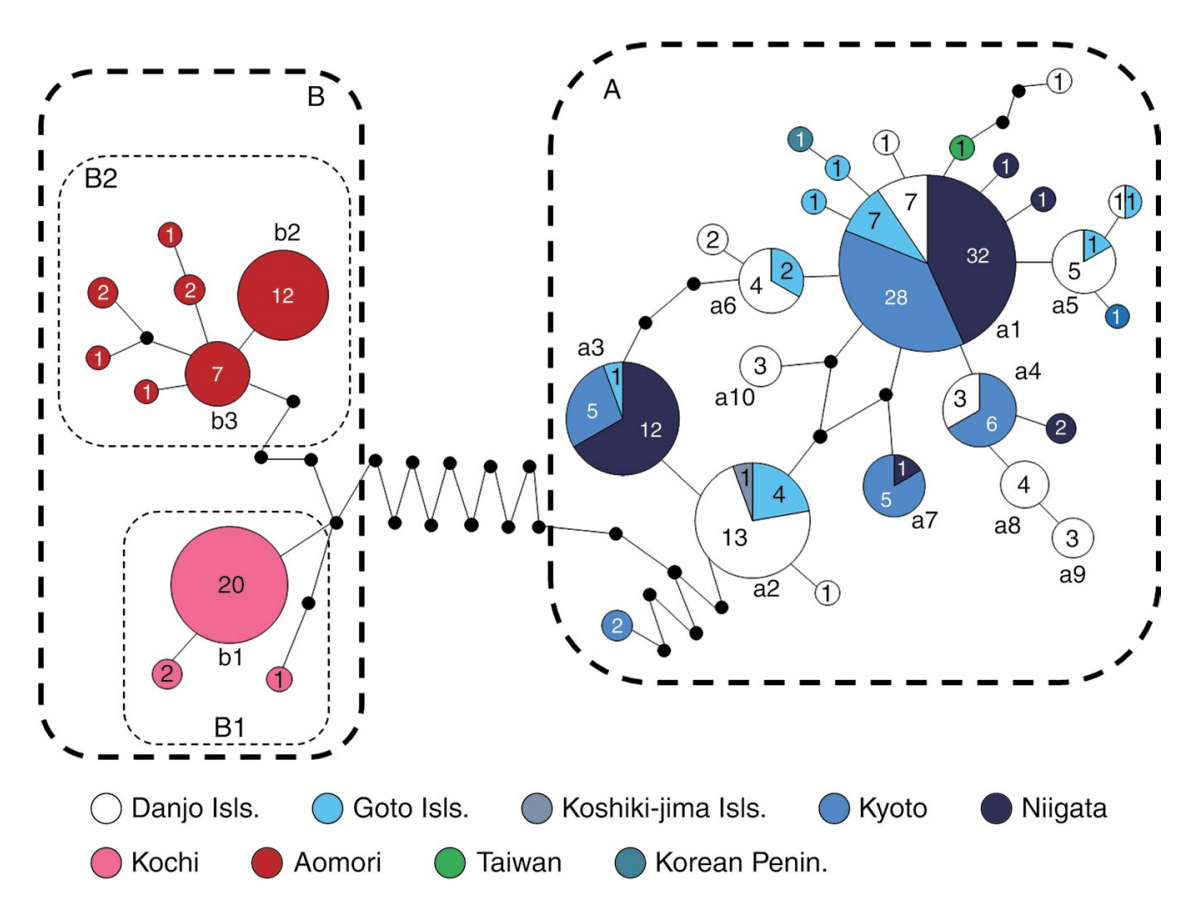

Figure 3

Minimum spanning network of haplotypes based on phylogenetic analysis of the mitochondrial cytochrome $b$ gene sequences (931 base pairs) identified in 214 polkadot skate (Dipturus chinensis). Sequences were obtained from specimens caught at 7 locations around Japan, in the East China Sea, Sea of Japan, and Pacific Ocean, between 2010 and 2017 or were obtained through the International Nucleotide Sequence Database Collaboration for 2 other populations, in Taiwan or off the Korean Peninsula. Each circle represents a unique haplotype. Haplotypes are combined into groups A and B, and group $\mathrm{B}$ is further divided into subgroups B1 and B2 (all of which correspond to the clades and subclades in the maximum likelihood tree in Figure 2). Slices of the circles represent fractions of the number of individuals of a haplotype that are associated with 1 or more of the 9 locations. The size of circles is proportional to the number of individuals. Each branch equals 1 nucleotide substitution. Isls.=Islands; Penin.=Peninsula. were excluded from analysis because the sample size for each location was only 1 individual. Results of hierarchical AMOVA (Suppl. Table 1) indicate that the $\Phi_{\mathrm{ST}}$ value was $0.8976(P<0.001)$ and that $89.76 \%$ of genetic variability was distributed among the 6 geographic populations that were included in analysis. When the 6 populations were divided into 2 groups, clade A (populations in the Danjo and Goto Islands in the East China Sea and populations in the Kyoto and Niigata Prefectures in the Sea of Japan) and clade B (populations in the Kochi and Aomori Prefectures along the southern and northern Pacific coasts of Japan, respectively), the $\Phi_{\mathrm{CT}}$ value was 0.8529 ( $\left.P=0.068\right)$, and $85.29 \%$ of genetic variability was distributed between the groups. When the 6 populations were divided into 3 groups, namely, clade A, clade B1 (population in Kochi Prefecture), and clade B2 (population in Aomori Prefecture), the $\Phi_{\mathrm{CT}}$ value was maximized $\left(\Phi_{\mathrm{CT}}=0.8964\right)$, and $89.64 \%$ of genetic variability was distributed between the groups. However, the $P$-value was barely not significant $(P=0.064)$.

The pairwise $\Phi_{\mathrm{ST}}$ values among the 6 geographic populations estimated from the mt cyt $b$ gene sequences are shown in Table 3. The values between each of the 2 populations along the Pacific coasts (in Kochi and Aomori Prefectures) and each of the 4 populations in the East China Sea (in the Danjo and Goto Islands) and the Sea of Japan (Kyoto and Niigata Prefectures) were high (pairwise $\Phi_{\mathrm{ST}}: 0.8847-$ 0.9342 ) and significant after a Bonferroni correction $(P<0.001)$. The $\Phi_{\mathrm{ST}}$ value between the populations in the Kochi and Aomori Prefectures was also high (pairwise $\Phi_{\mathrm{ST}}: 0.8507$ ) and significant after a Bonferroni correction $(P<0.001)$.

Demographic history The mismatch distributions for the samples in clade A (Fig. 5A) and clade B2 (Fig. 5C) follow a unimodal curve, and the distribution for the samples in clade B1 (Fig. 5B) has roughly an $L$ shape. Historic demographic parameters estimated for each clade are shown in Table 4 . The $\theta_{1}$ in clade B1 (0.299) was an order of magnitude smaller than that in clade A (3.916) and clade B2 (6.597). The sum of squared deviations and Harpending's raggedness index values were low and not significant in any of the distributions. The negative and significant values of Tajima's $D$ were detected for the samples for clade A (Tajima's $D$ : $-1.518, P<0.05$ ) and clade B1 (Tajima's $D:-1.679$, $P<0.05)$. The negative and significant values of Fu's $F$ s were detected for only the samples for clade A (Fu's Fs: -10.959 , $P<0.005)$.

The BSPs for clade A (Fig. 5D) and clade B2 (Fig. 5F) indicate that $N_{\mathrm{e}}$ increased after the Last Glacial Maximum (LGM, which occurred approximately 0.01-0.02 MYA), but such an increase of $N_{\mathrm{e}}$ with regard to LGM was not observed for clade B1 (Fig. 5E). However, the possibility of a constant population, a population that has not experienced rapid population growth or decline, could not be rejected for any clades because the $95 \%$ highest posterior density interval was not indicated to exclude zero by the parameter sum (indicators.alltrees).

\section{Microsatellite analyses}

Genetic variation within populations In the 6 geographic populations included in analysis, the mean number of alleles per locus ranged from 1.00 at locus LERI33 to 14.00 at locus LERI44 (Suppl. Table 2). No polymorphism 
A
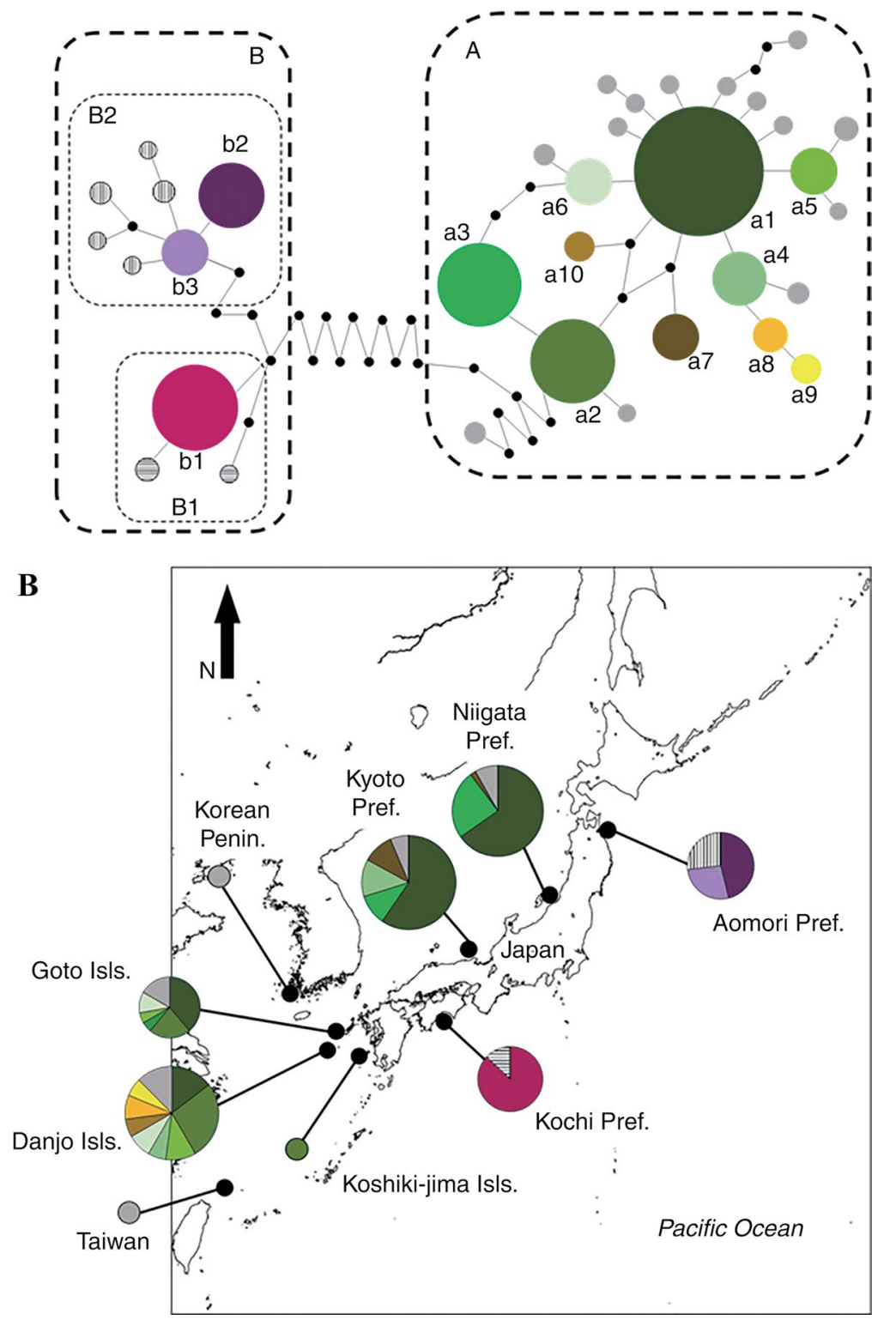

Figure 4

(A) A minimum spanning network of haplotypes and (B) a map of the geographic distribution of haplotypes based on phylogenetic analysis of the mitochondrial cytochrome $b$ gene sequences (931 base pairs) of polkadot skate (Dipturus chinensis). Sequences were obtained from specimens caught at 7 locations around Japan during 2010-2017 or were obtained through the International Nucleotide Sequence Database Collaboration for populations in Taiwan or off the Korean Peninsula. Circles of different colors represent the 13 major haplotypes. Gray circles and circles or slices of circles with horizontal or vertical lines represent rare (observed in 1 or 2 individuals) haplotypes in groups A, B1, and B2, respectively. Isls.=Islands; Penin.=Peninsula; Pref.=Prefecture. in Kyoto Prefecturue, with a mean of 8.70. The mean $A_{\mathrm{R}}$ for each geographic population varied from 6.01 for the population in Kochi Prefecture to 8.67 for the population in the Goto Islands, with a mean of 7.65. The mean $H_{\mathrm{O}}$ and $H_{\mathrm{E}}$ per locus varied from 0.484 at locus LERI21 to 0.857 at locus LERI44 and from 0.577 at locus LERI21 to 0.894 at locus LERI63, respectively. The mean $H_{\mathrm{O}}$ per geographic population ranged from 0.476 for the population in Kochi Prefecture to 0.681 for the population in Kyoto Prefecture. The mean $H_{\mathrm{E}}$ per geographic population ranged from 0.593 for the population in Aomori Prefecture to 0.804 for the population in the Danjo Islands, with heterozygosity gradually decreasing from the Danjo Islands in the East China Sea northward to Niigata Prefecture in the Sea of Japan. Significant deviation from the Hardy-Weinberg expectations due to homozygote excess was observed at 2 loci (LERI26 and LERI63). We deduced that these loci were affected by null alleles; therefore, they were also excluded from further analyses. For the 4 SSR loci (LERI21, LERI34, LERI44, and LERI50), no evidence of genotyping errors attributable to null alleles, stuttering, or large allele drop-out were observed. The results of pairwise comparisons between loci reveal no linkage disequilibrium.

Genetic differentiation among populations Results from hierarchical AMOVA (Suppl. Table 1) indicate that the $R_{\mathrm{ST}}$ value was $0.1409(P<0.001)$ and that $14.09 \%$ of genetic variability was distributed among the 6 geographic populations included in analysis. When the 6 populations were divided into 2 groups, clade $\mathrm{A}$ and clade $\mathrm{B}$, the $R_{\mathrm{CT}}$ value was $0.0868(P=0.067)$, and $8.68 \%$ of genetic variability was distributed between the groups. When the 6 populations were divided into 3 groups, clade $\mathrm{A}$, clade $\mathrm{B} 1$, and clade $\mathrm{B} 2$, the $R_{\mathrm{CT}}$ value was maximized $\left(R_{\mathrm{CT}}=0.1359\right)$, and $13.59 \%$ of genetic variability was distributed between the groups. However, the value was barely not significant $(P=0.066)$.

The pairwise $R_{\mathrm{ST}}$ values among the was observed at locus LERI33; therefore, this locus was not included in further analyses. The mean number of alleles per geographic population ranged from 6.33 for the population in Kochi Prefecture to 9.83 for the population 6 geographic populations estimated for 4 SSR loci are shown in Table 3 . The $R_{\mathrm{ST}}$ values between each of the 2 populations in the Pacific Ocean (in the Kochi and Aomori Prefectures) and each of the 4 populations in the East China Sea 


\section{Table 3}

Pairwise values of molecular genetic diversity among populations $\left(\Phi_{\mathrm{ST}}\right.$ and $R_{\mathrm{ST}}$ ) estimated from mitochondrial cytochrome $b$ gene (931 base pairs) (above the diagonal) and 4 microsatellite loci (below the diagonal), respectively, among 6 populations of the polkadot skate (Dipturus chinensis) sampled in the East China Sea, Sea of Japan, and Pacific Ocean during 2010-2017. An asterisk (*) indicates that a value is significant after a sequential Bonferroni correction $(P<0.001)$.

\begin{tabular}{lcccccc}
\hline Population location & Danjo Islands & Goto Islands & $\begin{array}{c}\text { Kyoto } \\
\text { Prefecture }\end{array}$ & $\begin{array}{c}\text { Niigata } \\
\text { Prefecture }\end{array}$ & $\begin{array}{c}\text { Kochi } \\
\text { Prefecture }\end{array}$ & $\begin{array}{c}\text { Aomori } \\
\text { Prefecture }\end{array}$ \\
\hline $\begin{array}{l}\text { Danjo Islands } \\
\text { Goto Islands }\end{array}$ & 0.0002 & -0.0030 & 0.0357 & 0.0269 & $0.8847^{*}$ & $0.8924^{*}$ \\
Kyoto Prefecture & 0.0029 & 0.0194 & 0.0037 & -0.0201 & $0.9342^{*}$ & $0.9234^{*}$ \\
Niigata Prefecture & 0.0093 & 0.0277 & 0.0031 & 0.0114 & $0.9147^{*}$ & $0.9156^{*}$ \\
Kochi Prefecture & $0.0806^{*}$ & $0.1060^{*}$ & $0.0800^{*}$ & $0.1325^{*}$ & & $0.9235^{*}$ \\
Aomori Prefecture & $0.1604^{*}$ & $0.1644^{*}$ & $0.1908^{*}$ & $0.2106^{*}$ & $0.1949^{*}$ & $0.8507^{*}$ \\
& & & & & & \\
\hline
\end{tabular}

(in the Danjo and Goto Islands) and in the Sea of Japan (in the Kyoto and Niigata Prefectures) were high (pairwise $\left.R_{\mathrm{ST}}: 0.0800-0.2106\right)$ and significant after a Bonferroni correction $(P<0.001)$. The $R_{\mathrm{ST}}$ value between the populations in the Kochi and Aomori Prefectures was also high (pairwise $R_{\mathrm{ST}}$ : 0.1949) and significant after a Bonferroni correction $(P<0.001)$.

\section{Discussion}

\section{Genetic variation}

The high $h$ and low $\pi$ (Table 2) in mt cyt $b$ observed in each geographic population, except for the one in Kochi Prefecture, correspond to the results from previous studies in which the same genetic region as the one used for polkadot skate in our study was used for thornback skate (Raja clavata) in Portugal and the southwestern part of the North Sea $(h=0.510-0.720, \pi=0.006-0.007$; Chevolot et al., 2006b) and for thorny skate in Newfoundland, Iceland, the northeastern part of the North Sea, and Kattegat ( $h=0.719-0.916, \pi=0.0030-0.0071$; Chevolot et al., 2007). In contrast, low $h$ and low $\pi$ observed in the population in the Kochi Prefecture are similar to the results for thornback skate in part of the Azores Islands and in the Mediterranean and Black Seas $(h=0.000, \pi=0.000$; Chevolot et al., 2006b). The mean $A_{\mathrm{R}}$ and $H_{\mathrm{E}}$ for each population from the SSR analysis in our study are higher than values reported by Griffiths et al. (2010) for the blue skate (D. batis) $\left(A_{\mathrm{R}}=3.65, H_{\mathrm{E}}=0.349\right)$ and the flapper skate $(D$. intermedius), which was treated as the northern clade of blue skate $\left(A_{\mathrm{R}}=3.35, H_{\mathrm{E}}=0.366\right)$, around the British Isles; Griffiths et al. (2010) used almost the same SSR loci as those used in our study. Among the 6 geographic populations in our study, the population in the Kochi Prefecture had the lowest $A_{\mathrm{R}}$, and $H_{\mathrm{E}}$ was relatively lower for this population than for the others. Although factors affecting low genetic diversity of the population in Kochi Prefecture are unclear, the low diversity may be related to the demographic history of the population (see the "Evolutionary history" section).

\section{Genetic differentiation among populations}

The maximum likelihood tree (Fig. 2) and the minimum spanning network (Fig. 3) based on the haplotypes of mt cyt $b$, reveal 3 lineages, clades A, B1, and B2. Clade A consists of populations in the East China Sea (populations in the Danjo and Goto Islands and 1 individual from the Koshikijima Islands) and in the Sea of Japan (populations in the Kyoto and Niigata Prefectures). The haplotypes observed for populations in Taiwan and off the Korean Peninsula were also included in clade A; however, there was only 1 sample each from those locations. Addition of more samples in analysis is needed to improve understanding of the genetic relationships of those geographic populations to the populations around Japan. Clade B1 is the population off the southern Pacific coast of Japan (in Kochi Prefecture), and clade B2 was made up of the population from the northern Pacific coast (in Aomori Prefecture). In both mt cyt $b$ and SSR analyses, the 6 geographic populations were separated into 3 groups, corresponding to the 3 clades, by using hierarchical AMOVA analyses that maximized $\Phi_{\mathrm{CT}}$ and $R_{\mathrm{CT}}$ values, respectively, although the values were barely not significant (Suppl. Table 1). Genetic differentiation among the 3 groups are also indicated by both the pairwise $\Phi_{\mathrm{ST}}$ and $R_{\mathrm{ST}}$ values from mt cyt $b$ and SSR analyses, respectively (Table 3).

Our results indicate that the population structure of the polkadot skate is influenced by the complicated oceanic currents that surround Japan (Fig. 1). The clades A, B1, and B2 around Japan can be regarded as the Tsushima, Kuroshio, and Oyashio lineages, respectively. Similar genetic differentiations between the populations in the Sea of Japan and along the Pacific coasts have been reported for ocellate spot skate (Misawa et al., 2019b), in addition to reports for several coastal fish and invertebrate species (Kojima et al., 1997, 2004; Akihito et al., 2008; Katafuchi et al., 2011; Kokita and Nohara, 2011; Hirase et al., 2012; 

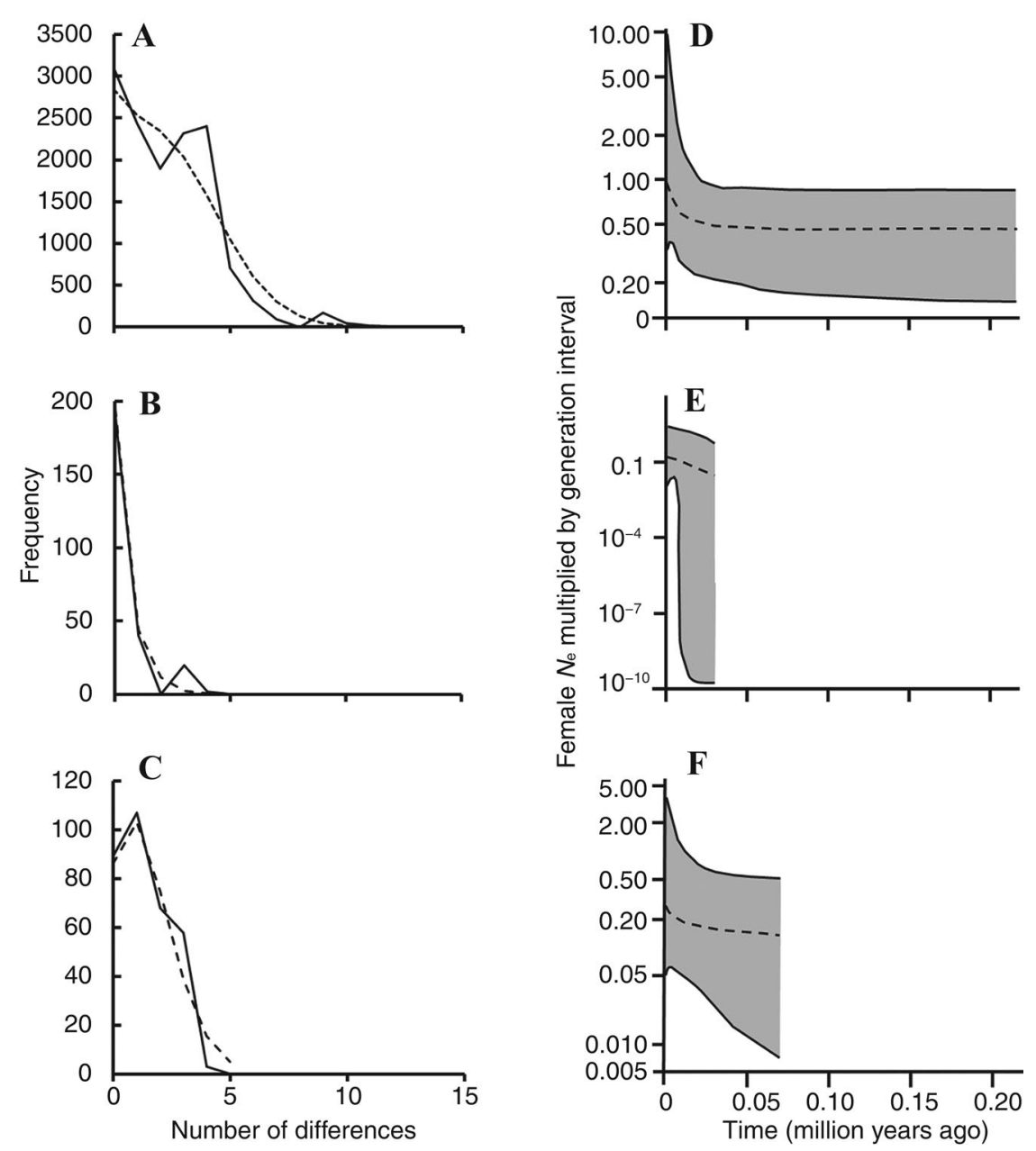

Figure 5

Mismatch distributions for (A) clade A, (B) clade B1, and (C) clade B2 of the polkadot skate (Dipturus chinensis) and Bayesian skyline plots for (D) clade A, (E) clade B1, and (F) clade B2, based on the mitochondrial cytochrome $b$ gene sequences (931 base pairs) of 214 individuals that were obtained from 7 locations around Japan between 2010 and 2017 or were obtained through the International Nucleotide Sequence Database Collaboration for populations in Taiwan or off the Korean Peninsula. In panels A-C, solid and dashed lines represent the observed and simulated distributions under the sudden expansion model, respectively. In panels D-F, dashed lines indicate the female effective population size $\left(N_{\mathrm{e}}\right)$ multiplied by the generation interval, and the shaded area indicates the $95 \%$ highest posterior density interval.

Hirase and Ikeda, 2014). Genetic divergence between the Sea of Japan and the East China Sea has not been indicated for the polkadot skate, but Misawa et al. (2019b) suggested that populations of ocellate spot skate diverge at the boundary of those seas. They suggested that the Tsushima Strait and the Tsushima Current act as geographic barriers for dispersal that can limit distribution of ocellate spot skate and that the Kuroshio Current may have prevented dispersal of that species because of the absence of a major population of ocellate spot skate from the Pacific coast of central Japan. Different from their influence on ocellate spot skate, the Tsushima and Kuroshio Currents may have an effect on the dispersal of polkadot skate (see the "Evolutionary history" section).

The population of polkadot skate on the Pacific coast of northern Honshu (Aomori Prefecture) can be regarded as the Oyashio lineage. In contrast, for some shallow-water organisms, the Tsushima lineage is the lineage distributed on the Pacific coast of northern Honshu (Kojima et al., 2004; Akihito et al., 2008; Katafuchi et al., 2011; Kokita and Nohara, 2011; Hirase et al., 2012; Hirase and Ikeda, 2014). The Tsugaru Warm Current, one of the branches 


\section{Table 4}

Results from mismatch distribution analysis and neutrality tests for 3 clades, based on phylogenetic analysis of mitochondrial cytochrome $b$ gene (931 base pairs), of the polkadot skate (Dipturus chinensis). The demographic parameters estimated for each clade in the mismatch distribution analysis include time since expansion in units of mutational time $(\tau)$ and population size before $\left(\theta_{0}\right)$ and after $\left(\theta_{1}\right)$ a rapid change in population size in units of mutational time (Rogers and Harpending, 1992; Schneider and Excoffier, 1999). The goodness of fit between the observed and expected distributions was tested by using the sum of squared deviations (SSD) and the Harpending's raggedness index (Hri). The neutrality of the sequence variation was verified by using Tajima's $D$ statistic and Fu's $F_{\mathrm{S}}$ test. $P$-values are provided in parentheses. DNA sequences were obtained from specimens collected around Japan, in the East China Sea, Sea of Japan, and Pacific Ocean, during 2010-2017 or were obtained through the International Nucleotide Sequence Database Collaboration for populations in Taiwan or off the Korean Peninsula.

\begin{tabular}{|c|c|c|c|c|c|c|c|c|}
\hline \multirow[b]{3}{*}{ Group } & \multicolumn{6}{|c|}{ Mismatch distribution } & & \\
\hline & \multirow[b]{2}{*}{$\tau$} & \multirow{2}{*}{$\begin{array}{c}\text { Mismatch } \\
\text { observed mean }\end{array}$} & \multirow[b]{2}{*}{$\theta_{0}$} & \multirow[b]{2}{*}{$\theta_{1}$} & \multicolumn{2}{|c|}{ Test of goodness of fit } & \multicolumn{2}{|c|}{ Neutrality tests } \\
\hline & & & & & $\operatorname{SSD}(P)$ & $\operatorname{Hri}(P)$ & Tajima's $D(P)$ & Fu's $F_{\mathrm{s}}(P)$ \\
\hline Clade A & 3.695 & 2.314 & 0.000 & 3.916 & $0.007(0.686)$ & $0.022(0.893)$ & $-1.518(0.037)$ & $-10.959(0.002)$ \\
\hline Clade B1 & 3.000 & 0.427 & 0.000 & 0.299 & $0.007(0.334)$ & $0.393(0.572)$ & $-1.679(0.024)$ & $-0.413(0.248)$ \\
\hline Clade B2 & 1.533 & 1.320 & 0.072 & 6.597 & $0.006(0.578)$ & $0.047(0.798)$ & $-0.858(0.221)$ & $-2.025(0.089)$ \\
\hline
\end{tabular}

of the Tsushima Current, passes eastward through the Tsugaru Strait and runs into the Oyashio Current east of the Tsugaru Strait, forcing it to flow southward along the eastern coast of northern Honshu. The distribution of the Tsushima lineage of various marine animals on the Pacific coast of northern Honshu is considered to be influenced by the Tsugaru Warm Current (Kojima et al., 2004; Akihito et al., 2008; Katafuchi et al., 2011; Kokita and Nohara, 2011; Hirase et al., 2012). In contrast, a genetic differentiation between the western and eastern populations of northern Honshu has been suggested for the ocellate spot skate, the Pacific sandlance (Ammodytes personatus), and a zoarcid fish, Davidijordania poecilimon (Han et al., 2012; Kai et al., 2014; Misawa et al., 2019b), as well as for the polkadot skate as indicated by our results.

The dispersal of species is affected by many factors, including the environmental requirements and life histories of species. Kai et al. (2014) suggested that gene flow between the Sea of Japan and the Pacific populations of D. poecilimon is restricted by the shallow Tsugaru Strait (which has a maximum depth of approximately $150 \mathrm{~m}$ ) because this deep-sea species is found in depths of less than $262 \mathrm{~m}$ (Shinohara et al., 1996). The normal habitat depths of polkadot skate (mainly 20-150 m; Hatooka et al., 2013) and ocellate spot skate (mainly 30-100 m; Last et al., 2016) are shallower than that of $D$. poecilimon, and their migrations are not as restricted by the shallow strait as that of $D$. poecilimon. The clear genetic divergence in polkadot skate and the restricted gene flow in ocellate spot skate (Misawa et al., 2019b) between the western and eastern populations of northern Honshu may be partly because of the lack of pelagic eggs and the larval stage of rajids (Ishiyama, 1967).

For polkadot skate, results of our study indicate a divergence between the southern (clade B1) and northern (clade B2) populations on the Pacific coast of Honshu. The existence of geologically discrete lineages on this coast of Honshu has been suggested for some coastal fish species (Katafuchi et al., 2011; Han et al., 2012; Hirase et al., 2012; Hirase and Ikeda, 2014). Among them, lineages of surfperch and goby species have been reported to be separated by the Izu Peninsula (Katafuchi et al., 2011; Hirase et al., 2012). Hirase et al. (2012) suggested that the shallow coastal areas in bays east and west of the Izu Peninsula, suitable for a goby species, likely disappeared owing to the sea level fall in the Pleistocene glacial periods, a change that resulted in vicariant separation.

In contrast, Han et al. (2012) detected a boundary between the lineages in the transition zone between the Kuroshio and Oyashio Currents and suggested that sea temperature is a key factor preventing the dispersal of the lineage that dominates the northern group of Pacific sandlance. The Kuroshio Current is subtropical and saline, and the Oyashio Current is subarctic and less saline (GSI, 1990). Results of the studies of the genetic population structure of mottled skate (Im et al., 2017; Misawa et al., 2019a) indicate that temperature gradients potentially affect the allopatric distributions of lineages. In thorny skate, genetic differentiation is reportedly caused by differences in salinity and temperature (Chevolot et al., 2007). The divergence between the southern (clade B1) and northern (clade B2) populations of polkadot skate on the Pacific coast of Honshu was probably due to environmental differences, such as differences in temperature and salinity between the Kuroshio and Oyashio Currents.

\section{Evolutionary history}

For polkadot skate, the divergence time between clade $\mathrm{A}$ and clade B was estimated to be 1.31-2.10 MYA in the Early Pleistocene. Some changes in land area with respect to glacio-eustatic sea-level fluctuation occurred in the 
Quaternary period (from 2.58 MYA to present). In the Early to Middle Pleistocene (0.78-2.58 MYA), the main islands of Japan were connected to the continent of Asia, and the Ryukyu Islands were connected to the continent of Asia through Taiwan, by large land bridges, repeatedly (Kizaki and Oshiro, 1977, 1980; Ujiie, 1986; Kimura, 1996, 2000). Clade A likely became differentiated in the semiclosed environment of the East China Sea and dispersed northward when the southern straits of the Sea of Japan opened. Clade B might have extended its distribution northward along the Pacific coast after divergence from clade A and divided into clades B1 and B2 approximately 0.50-0.80 MYA in the Middle Pleistocene. The divergence of clades B1 and B2 may have been caused by changes in the dynamic of the ancient Oyashio Current, which strengthened during 0.48-0.34 MYA (Matsuzaki et al., 2014); afterward, the Kuroshio Current dominated 0.780.85 MYA (Kang et al., 2010; Gallagher et al., 2015). Clade $B$ extended its distribution northward along the coast of Honshu with the Kuroshio Current but was prevented from further extension to the north by the strengthened Oyashio Current approximately 0.5 MYA, and the Kuroshio (clade B1) and the Oyashio (clade B2) lineages diverged.

Although the results of the mismatch distribution analysis, the neutrality tests (Table 4), and the combination of high $h$ and low $\pi$ values (Table 2) (Grant and Bowen, 1998) indicate a population expansion of clade A (Table 4, Fig. $5 \mathrm{~A}$ ), the possibility of a constant population could not be rejected in the $\mathrm{BSP}$ (Fig. 5D). However, the BSP for clade A indicates that $N_{\mathrm{e}}$ notably increased after LGM, and clade A may have expanded its distribution from the East China Sea to the Sea of Japan after LGM. The gradual decrease of genetic diversity ( $h$ in mtDNA analysis and $H_{\mathrm{E}}$ in SSR analysis) in populations of polkadot skate from the Danjo Islands in the East China Sea northward to Niigata Prefecture in the Sea of Japan (Table 2, Fig. 4, Suppl. Table 2) may have been due to a founder event or to differences in adaptive abilities, such as tolerance to cold temperatures as frequencies of restricted haplotypes (haplotypes a1 and a3) increase with increasing latitude (Fig. 4). Similar declines in genetic diversity toward the north in the Sea of Japan have been reported for the sailfin sandfish (Arctoscopus japonicus) (see Shirai et al., 2006) and a rocky intertidal goby, Chaenogobius gulosus (see Hirase and Ikeda, 2014).

Although sum of squared deviations and the Harpending's raggedness index are not significant and Fu's $F$ s does not indicate certain departures from neutrality in clade B1 (Table 4), the mismatch distributions (Fig. 5B) roughly have an $L$ shape, indicating that clade B1 had experienced a population bottleneck (Rogers and Harpending, 1992). The combination of low $h$ and low $\pi$ values observed in clade B1 (Table 2) also indicates a recent population bottleneck or founder event for a single or a few mtDNA lineages (Grant and Bowen, 1998). However, no signal of population bottleneck is apparent in the BSP (Fig. $5 \mathrm{E})$. In any case, $N_{\mathrm{e}}$ in clade B1 did not notably increase after LGM, and $N_{\mathrm{e}}$ in clade B1 is considerably smaller at present than $N_{\mathrm{e}}$ for the other clades, according to values for $\theta_{1}$ (Table 4) and the BSP. The low genetic diversity in both mtDNA and SSR analyses for clade B1 was related to the small $N_{\mathrm{e}}$ of the clade. In clade B2, the population expansion could not be inferred by using neutrality tests (Table 4); however, results of the mismatch distribution analysis (Table 4, Fig. 5C) and the combination of high $h$ and low $\pi$ values (Table 2 ) indicate that the population expanded (Rogers and Harpending, 1992; Grant and Bowen, 1998). Although the possibility of a constant population could not be rejected in the BSP (Fig. 5F), the BSP for clade B2, as well as that for clade A, indicates that $N_{\mathrm{e}}$ increased after LGM (Fig. 5D).

\section{Implications for management and conservation}

The application of genetic and evolutionary measures in the conservation and management of natural resources has led to the identification of management units (MUs), which represent populations or groups of populations that are connected by low levels of gene flow and are functionally independent (Moritz, 1994, 2002). Significant population structure in the polkadot skate was observed around Japan in our study, and we suggest considering the existence of a minimum of $3 \mathrm{MUs}$ for this species: the group of populations in the Sea of Japan and the East China Sea, the population along the southern Pacific coast, and the population along the northern Pacific coast. Each MU possesses unique genetic traits and, therefore, should be treated independently. Particularly, the MU for the population along the southern Pacific coast is characterized by genetic diversity that is lower than that of the other 2 MUs and should be monitored and managed more carefully. Ecological studies, such as those that focus on age, growth, reproduction, and movement patterns, for each MU are also necessary to establish appropriate conservation and management strategies.

\section{Conclusions}

We examined the genetic population structure of polkadot skate around Japan. Results of the mtDNA analysis of polkadot skate indicate that this species has 3 lineages, clades A, B1, and B2. Clade A consists of populations in the Sea of Japan and the East China Sea. Clades B1 and B2 comprise populations in the Pacific Ocean along the southern and northern coasts of Japan, respectively. This genetic differentiation is also supported by results from SSR analysis. Results of this study indicate that the divergence between clades A and B occurred because of isolation of the East China Sea in the Early Pleistocene and that the divergence between clades B1 and B2 occurred likely because of changes in the dynamics of ancient water currents in the Middle Pleistocene. Each of the 3 genetically discrete management units of polkadot skate around Japan possess unique genetic traits and evolutionary history, and each should be treated independently in management of this species in the future. 


\section{Acknowledgments}

We thank H. Kanehara, T. Aoshima, G. Kume, and the staffs of the training ships Nagasaki-Maru (Nagasaki University) and Kagoshima-Maru (Kagoshima University), the staffs of the RV Mizuho-Maru (Japan Sea National Fisheries Research Institute) and the RV Heian-Maru (Kyoto Institute of Oceanic and Fishery Science), and trawl fishermen of the FV Kosei-Maru (Mimase, Kochi Prefecture) and FV Kyuei-Maru (Hachinohe, Aomori Prefecture) for collecting samples. This work was supported in part by the Japan Fisheries Agency.

\section{Literature cited}

Akihito, A. Fumihito, Y. Ikeda, M. Aizawa, T. Makino, Y. Umehara, Y. Kai, Y. Nishimoto, M. Hasegawa, T. Nakabo, et al.

2008. Evolution of Pacific Ocean and the Sea of Japan populations of the gobiid species, Pterogobius elapoides and Pterogobius zonoleucus, based on molecular and morphological analyses. Gene 427:7-18. Crossref

Bouckaert, R., J. Heled, D. Kühnert, T. Vaughan, C.-H. Wu, D. Xie, M. A. Suchard, A. Rambaut, and A. J. Drummond.

2014. BEAST 2: a software platform for Bayesian evolutionary analysis. PLoS Comput. Biol. 10(4):e1003537. Crossref

Brander, K.

1981. Disappearance of common skate Raja batis from Irish Sea. Nature 290:48-49. Crossref

Chevolot, M., J. R. Ellis, G. Hoarau, A. D. Rijnsdorp, W. T. Stam, and J. L. Olsen.

2006a. Population structure of the thornback ray (Raja clavata L.) in British waters. J. Sea Res. 56:305-316. Crossref

Chevolot, M., G. Hoarau, A. D. Rijnsdorp, W. T. Stam, and J. L.

Olsen.

2006b. Phylogeography and population structure of thornback rays (Raja clavata L., Rajidae). Mol. Ecol. 15:36933705. Crossref

Chevolot, M., P. H. J. Wolfs, J. Pálsson, A. D. Rijnsdorp, W. T. Stam, and J. L. Olsen.

2007. Population structure and historical demography of the thorny skate (Amblyraja radiata, Rajidae) in the North Atlantic. Mar. Biol. 151:1275-1286. Crossref

Clement, M., D. Posada, and K. A. Crandall.

2000. TCS: a computer program to estimate gene genealogies. Mol. Ecol. 9:1657-1659. Crossref

Domingues, R. R. D., A. W. S. Hilsdorf, and O. B. F. Gadig. 2018. The importance of considering genetic diversity in shark and ray conservation policies. Conserv. Genet. 19:501-525. Crossref

Drummond, A. J., A. Rambaut, B. Shapiro, and O. G. Pybus.

2005. Bayesian coalescent inference of past population dynamics from molecular sequences. Mol. Biol. Evol. 22:1185-1192. Crossref

Dulvy, N. K., J. D. Metcalfe, J. Glanville, M. G. Pawson, and J. D.

Reynolds.

2000. Fishery stability, local extinctions, and shifts in community structure in skates. Conserv. Biol. 14:283-293. Crossref

El Nagar, A., M. McHugh, T. Rapp, D. W. Sims, and M. J. Genner. 2010. Characterisation of polymorphic microsatellite markers for skates (Elasmobranchii: Rajidae) from expressed sequence tags. Conserv. Genet. 11:1203-1206. Crossref
Excoffier, L., and H. E. L. Lischer.

2010. Arlequin suite ver 3.5: a new series of programs to perform population genetics analyses under Linux and Windows. Mol. Ecol. Resour. 10:564-567. Crossref

Excoffier, L., P. E. Smouse, and J. M. Quattro.

1992. Analysis of molecular variance inferred from metric distances among DNA haplotypes: application to human mitochondrial DNA restriction data. Genetics 131:479-491.

Felsenstein, J.

1985. Confidence limits on phylogenies: an approach using bootstrap. Evolution 39:783-791. Crossref

Ferrari, A., F. Tinti, V. B. Maresca, A. Velonà, R. Cannas, I. Thasitis, F. O. Costa, M. C. Follesa, D. Golani, F. Hemida, et al.

2018. Natural history and molecular evolution of demersal Mediterranean sharks and skates inferred by comparative phylogeographic and demographic analyses. PeerJ 6:e5560. Crossref

Frodella, N., R. Cannas, A. Vilonà, P. Carbonara, E. D. Farrell, F. Fiorentino, M. C. Follesa, G. Garofalo, F. Hemida, C. Mancusi, et al.

2016. Population connectivity and pylogeography of the Mediterranean endemic skate Raja polystigma and evidence of its hybridization with the parapatric sibling $R$. montagui. Mar. Ecol. Prog. Ser. 554:99-113. Crossref

$\mathrm{Fu}, \mathrm{Y} . \mathrm{X}$.

1997. Statistical tests of neutrality of mutations against population growth, hitchhiking and background selection. Genetics 147:915-925.

Gallagher, S. J., A. Kitamura, Y. Iryu, T. Itaki, I. Koizumi, and P.

W. Hoiles.

2015. The Pliocene to recent history of the Kuroshio and Tsushima currents: a multi-proxy approach. Prog. Earth Planet. Sci. 2:17. Crossref

Goudet, J.

2002. FSTAT: a program to estimate and test gene diversities and fixation indices, vers. 2.9.3.2. [Available from website, accessed September 2018.]

Grant, W. A. S., and B. W. Bowen.

1998. Shallow population histories in deep evolutionary lineages of marine fishes: insights from sardines and anchovies and lessons for conservation. J. Hered. 89:415-426. Crossref

Griffiths, A. M., D. W. Sims, S. P. Cotterell, A. El Nagar, J. R. Ellis, A. Lynghammar, M. McHugh, F. C. Neat, N. G. Pade, N. Queiroz, et al.

2010. Molecular markers reveal spatially segregated cryptic species in a critically endangered fish, the common skate (Dipturus batis). Proc. R. Soc., B 277:1497-1503. Crossref

Griffiths, A. M., D. W. Sims, A. Johnson, A. Lynghammar, M. McHugh, T. Bakken, and M. J. Genner.

2011. Levels of connectivity between longnose skate (Dipturus oxyrinchus) in the Mediterranean Sea and the north-eastern Atlantic Ocean. Conserv. Genet. 12:577-582. Crossref

GSI (Geographical Survey Institute).

1990. The national atlas of Japan, rev. ed., 219 p. GSI, Tokyo, Japan. [Available from website.]

Guo, S. W., and E. A. Thompson.

1992. Performing the exact test for Hardy-Weinberg proportion for multiple alleles. Biometrics 48:361-372. Crossref

Han, Z., T. Yanagimoto, Y. Zhang, and T. Gao.

2012. Phylogeography study of Ammodytes personatus in northwestern Pacific: Pleistocene isolation, temperature and current conducted secondary contact. PLoS ONE 7(5):e37425. Crossref 
Hara, K., K. Furumitsu, and A. Yamaguchi.

2014. Record of a Korean skate, Hongeo koreana (Jeong and Nakabo, 1997) from off Goto islands. Rep. Jap. Soc. Elasmobranch Stud. 50:21-26. [In Japanese.]

Hara, K., K. Furumitsu, T. Aoshima, H. Kanehara, and A. Yamaguchi.

2018a. Age, growth, and age at sexual maturity of the commercially landed skate species, Dipturus chinensis (Basilewsky, 1855), in the northern East China Sea. J. Appl. Ichthyol. 34:66-72. Crossref

Hara, K., K. Furumitsu, and A. Yamaguchi.

2018b. Dietary habits of the polkadot skate Dipturus chinensis in the East China Sea. Ichthyol. Res. 65:363-373. Crossref

Harpending, H. C.

1994. Signature of ancient population growth in a lowresolution mitochondrial DNA mismatch distribution. Hum. Biol. 66:591-600.

Hatooka, K., U. Yamada, M. Aizawa, A. Yamaguchi, and N. Yagishita.

2013. Rajidae. In Fishes of Japan with pictorial keys to the species, 3rd ed. (T. Nakabo, ed.), p. 205-216, 1771-1773. Tokai Univ. Press, Hadano, Japan. [In Japanese.]

Hirase, S., and M. Ikeda.

2014. Divergence of mitochondrial DNA lineage of the rocky intertidal goby Chaenogobius gulosus around the Japanese Archipelago: reference to multiple Pleistocene isolation events in the Sea of Japan. Mar. Biol. 161:565-574. Crossref

Hirase, S., M. Ikeda, M. Kanno, and A. Kijima.

2012. Phylogeography of the intertidal goby Chaenogobius annularis associated with paleoenvironmental changes around the Japanese Archipelago. Mar. Ecol. Prog. Ser. 450:167-179. Crossref

Im, Y.-J., H.-S. Jo, H.-S. Ji, S.-H. Myoung, and J.-K. Kim.

2017. Geographic variations of the mottled skate, Beringraja pulchra (Liu, 1932) (Rajidae) in the Yellow and East Seas based on molecular and morphometric data. J. Appl. Ichthyol. 33:950-956. Crossref

Ishiyama, $R$.

1967. Fauna Japonica. Rajidae (Pisces), 82 p. Biogeogr. Soc. Jap., Tokyo, Japan.

Jeong, C. H., and H. Ishihara.

2009. Dipturus kwangtungensis. The IUCN Red List of Threatened Species 2009. e.T161400A5415674. [Available from website, accessed January 2017.]

Jeong, D., and Y.-H. Lee.

2015. The complete mitochondrial genome of the longnose skate: Raja rhina (Rajiformes, Rajidae). Mitochondrial DNA 26:123-124. Crossref

Jeong, D., S. Kim, C.-G. Kim, and Y.-H. Lee.

2014. The complete mitochondrial genome of the Korean skate: Hongeo koreana (Rajiformes, Rajidae). Mitochondrial DNA 25:437-438. Crossref

2015. Complete mitochondrial genome of the Kwangtung skate: Dipturus kwangtungensis (Rajiformes, Rajidae). Mitochondrial DNA 26:873-874. Crossref

Kai, Y., Y. Ueda, K. Fujiwara, M. Itoh, A. Yamasaki, and T. Nakabo. 2014. Population structure and demographic history of Davidijordania poecilimon (Perciformes: Zoarcidae). Species Divers. 19:15-19. Crossref

Kang, S., D. Lim, and S.-Y. Kim.

2010. Benthic foraminiferal assemblage of Seogwipo Formation in Jeju Island, South Sea of Korea: implication for late Pliocene to early Pleistocene cold episode in the northwestern Pacific margin. Quat. Int. 225:138-146. Crossref
Katafuchi, H., Y. Kai, and T. Nakabo.

2011. Genetic divergence in Ditrema jordani (Perciformes: Embiotocidae) from the Pacific coast of southern Japan, as inferred from mitochondrial DNA sequences. Ichthyol. Res. 58:90-94. Crossref

Kim, I.-C., S.-O. Jung, Y.-M. Lee, C.-J. Lee, J.-K. Park, and J.-S. Lee.

2005. The complete mitochondrial genome of the rayfish Raja porosa (Chondrichthyes, Rajidae). DNA Sequence 16:187194. Crossref

Kimura, M.

1996. Quaternary paleogeography of the Ryukyu Arc. J. Geogr. 105:259-285. [In Japanese.] Crossref

2000. Paleogeography of the Ryukyu Islands. Tropics 10:524. Crossref

Kizaki, K., and I. Oshiro.

1977. Paleogeography of the Ryukyu Islands. Mar. Sci. Mon. 9:542-549. [In Japanese.]

1980. The origin of the Ryukyu Islands. In Natural history of the Ryukyus (K. Kizaki, ed.), p. 8-37. Tsukiji-shokan, Tokyo, Japan. [In Japanese.]

Kojima, S., R. Segawa, and I. Hayashi.

1997. Genetic differentiation among populations of the Japanese turban shell Turbo (Batillus) cornutus corresponding to warm currents. Mar. Ecol. Prog. Ser. 150:149-155. Crossref

Kojima, S., I. Hayashi, D. Kim, A. Iijima, and T. Furota.

2004. Phylogeography of an intertidal direct-developing gastropod Batillaria cumingi around the Japanese Islands. Mar. Ecol. Prog. Ser. 276:161-172. Crossref

Kokita, T., and K. Nohara.

2011. Phylogeography and historical demography of the anadromous fish Leucopsarion petersii in relation to geological history and oceanography around the Japanese Archipelago. Mol. Ecol. 20:143-164. Crossref

Larkin, M. A., G. Blackshields, N. P. Brown, R. Chenna, P. A. McGettigan, H. McWilliam, F. Valentin, I. M. Wallace, A. Wilm, R. Lopez, et al.

2007. Clustal W and Clustal X version 2.0. Bioinformatics 23:2947-2948. Crossref

Last, P. R., and A. P.K. Lim.

2010. A new species of skate Okamejei jensenae sp. nov. (Rajoidei: Rajidae) from the seas off Borneo, with a redescription of the Kwangtung skate, Dipturus kwangtungensis (Chu). In Descriptions of new sharks and rays from Borneo (P. R. Last, W. T. White, and J. J. Pogonoski, eds.), p. 101-114. CSIRO Mar. Atmos. Res. Pap. 032

Last, P. R., B. Séret, M. F. W. Stehmann, and S. Weigmann.

2016. Skates: family Rajidae. In Rays of the world (P. R. Last, W. T. White, M. R. de Carvalho, B. Séret, M. F. W. Stehmann, and G. J. P. Naylor, eds.), p. 204-363. CSIRO Publ., Clayton, Australia.

Matsuzaki, K. M., H. Nishi, N. Suzuki, G. Cortese, F. Eynaud, R. Takashima, Y. Kawate, and T. Sakai.

2014. Paleoceanographic history of the Northwest Pacific Ocean over the past $740 \mathrm{kyr}$, discerned from radiolarian fauna. Palaeogeogr. Palaeoclimatol. Palaeoecol. 396:26-40. Crossref

Misawa, R., N. Muto, T. Hamatsu, J.-K. Kim, and Y. Kai.

2019a. Genetic population structure and morphological differences in the mottled skate Beringraja pulchra. Jap. J. Ichthyol. 66:23-35. [In Japanese.] Crossref

Misawa, R., Y. Narimatsu, H. Endo, and Y. Kai.

2019b. Population structure of the ocellate spot skate (Okamejei kenojei) inferred from variations in mitochondrial DNA (mtDNA) sequences and from morphological characters of regional populations. Fish. Bull. 117:24-36. Crossref 
Misawa, R., A. M. Orlov, S. Y. Orlova, I. I. Gordeev, H. Ishihara, T. Hamatsu, Y. Ueda, K. Fujiwara, H. Endo, and Y. Kai.

2020. Bathyraja (Arctoraja) sexoculata sp. nov., a new softnose skate (Rajiformes: Arhynchobatidae) from Simushir Island, Kuril Islands (western North Pacific), with special reference to geographic variations in Bathyraja (Arctoraja) smirnovi. Zootaxa 4861:515-543. Crossref

Moritz, C.

1994. Defining 'evolutionarily significant units' for conservation. Trends Ecol. Evol. 9:373-374. Crossref

2002. Strategies to protect biological diversity and the evolutionary processes that sustain it. Syst. Biol. 51:238-254. Crossref

Nei, M.

1987. Molecular evolutionary genetics, 512 p. Columbia Univ. Press, New York.

Nei, M., and W.-H. Li.

1979. Mathematical model for studying genetic variation in terms of restriction endonucleases. Proc. Natl. Acad. Sci. U.S.A. 76:5269-5273. Crossref

Nei, M., and J. C. Miller.

1990. A simple method for estimating average number of nucleotide substitutions within and between populations from restriction data. Genetics 125:873-879.

Palsbøll, P. J., M. Bérubé, and F. W. Allendorf.

2007. Identification of management units using population genetic data. Trends Ecol. Evol. 22:11-16. Crossref

Palumbi, S., A. Martin, S. Romano, W. O. McMillan, L. Stice, and

G. Grabowski.

2002. The simple fool's guide to PCR, vers. 2.0, 45 p. Univ. Hawaii Press, Honolulu, HI.

Rambaut, A., A. J. Drummond, D. Xie, G. Baele, and M. A. Suchard. 2018. Posterior summarization in Bayesian phylogenetics using Tracer 1.7. Syst. Biol. 67:901-904. Crossref

Rasmussen, A.-S., and U. Arnason.

1999. Molecular studies suggest that cartilaginous fishes have a terminal position in the piscine tree. Proc. Natl. Acad. Sci. U.S.A. 96:2177-2182. Crossref

Raymond, M., and F. Rousset.

1995. GENEPOP (version 1.2): population genetics software for exact tests and ecumenicism. J. Hered. 86:248-249. Crossref

Rice, W. R.

1989. Analyzing tables of statistical tests. Evolution 43:223-225.

Rogers, A. R., and H. Harpending.

1992. Population growth makes waves in the distribution of pairwise genetic differences. Mol. Biol. Evol. 9:552-569. Crossref

Rousset, F.

2008. GENEPOP'007: a complete re-implementation of the GENEPOP software for Windows and Linux. Mol. Ecol. Resour. 8:103-106. Crossref

Schneider, S., and L. Excoffier.

1999. Estimation of past demographic parameters from the distribution of pairwise differences when the mutation rates vary among sites: application to human mitochondrial DNA. Genetics 152:1079-1089.
Shinohara, G., H. Endo, and K. Matsuura.

1996. Deep-water fishes collected from the Pacific coast of northern Honshu, Japan. Mem. Natl. Sci. Mus., Tokyo 29:153-185.

Shirai, S. M., R. Kuranaga, H. Sugiyama, and M. Higuchi. 2006. Population structure of the sailfin sandfish, Arctoscopus japonicus (Trichodontidae), in the Sea of Japan. Ichthyol. Res. 53:357-368. Crossref

Tajima, F.

1989a. Statistical method for testing the neutral mutation hypothesis by DNA polymorphism. Genetics 123:585-595.

1989b. The effect of change in population size on DNA polymorphism. Genetics 123:597-601.

Tamura, K., and M. Nei.

1993. Estimation of the number of nucleotide substitutions in the control region of mitochondrial DNA in humans and chimpanzees. Mol. Biol. Evol. 10:512-526. Crossref

Tamura, K., G. Stecher, D. Peterson, A. Filipski, and S. Kumar. 2013. MEGA6: molecular evolutionary genetics analysis version 6.0. Mol. Biol. Evol. 30:2725-2729. Crossref

Tokimura, M., M. Ito, and U. Yamada.

1998. New record of the rajid fish, Raja koreana Jeong and Nakabo (new Japanese name: Kourai-kasube) from Japan. Seikaiku Suisan Kenkyusho News 93:9-10. [In Japanese.] [Available from website.]

Ujiie, $\mathrm{H}$.

1986. Beneath the Ryukyu Island Arc: sedimentology and geology, 120 p. Shinsei-tosho, Naha, Japan. [In Japanese.]

Van Oosterhout, C., W. F. Hutchinson, D. P. M. Wills, and P. Shipley. 2004. MICRO-CHECKER: software for identifying and correcting genotyping errors in microsatellite data. Mol. Ecol. Notes 4:535-538. Crossref

Vargas-Caro, C., C. Bustamante, J. Lamilla, M. B. Bennett, and J. R. Ovenden.

2016. The phylogenetic position of the roughskin skate Dipturus trachyderma (Krefft \& Stehmann, 1975) (Rajiformes, Rajidae) inferred from the mitochondrial genome. Mitochondrial DNA, A 27:2965-2966. Crossref

Vargas-Caro, C., C. Bustamante, M. B. Bennett, and J. R. Ovenden. 2017. Towards sustainable fishery management for skates in South America: the genetic population structure of Zearaja chilensis and Dipturus trachyderma (Chondrichthyes, Rajiformes) in the south-east Pacific Ocean. PLoS ONE 12(2):e0172255. Crossref

Weltz, K., J. M. Lyle, J. M. Semmens, and J. R. Ovenden.

2018. Population genetics of the endangered Maugean skate (Zearaja maugeana) in Macquarie Harbour, Tasmania. Conserv. Genet. 19:1505-1512. Crossref

Yamada, U., M. Tokimura, H. Horikawa, and T. Nakabo. 2007. Fishes and fisheries of the East China and Yellow Seas, 1262 p. Tokai Univ. Press, Hadano, Japan. [In Japanese.]

Yamada, U., M. Tokimura, K. Hoshino, S. M. Deng, Y. J. Zheng, S. F. Li, Y. S. Kim, and J. K. Kim.

2009. Names and illustrations of fishes from the East China Sea and the Yellow Sea-Japanese/Chinese/Korean, new ed., 784 p. Overseas Fish. Coop. Found. Japan, Tokyo, Japan. 